\title{
Rising Above Misinformation or Fake News in Africa: Another Strategy to Control COVID-19 Spread
}

\author{
Bright Opoku Ahinkorah ${ }^{1}$, Edward Kwabena Ameyaw ${ }^{1}$, John Elvis Hagan Jr. ${ }^{2,3 *}$, \\ Abdul-Aziz Seidu ${ }^{4}$ and Thomas Schack ${ }^{3}$ \\ ${ }^{1}$ The Australian Centre for Public and Population Health Research [ACPPHR], Faculty of Health, University of Technology \\ Sydney, Ultimo, NSW, Australia, ${ }^{2}$ Department of Population and Health, University of Cape Coast, Cape Coast, Ghana, \\ ${ }^{3}$ Neurocognition and Action-Biomechanics-Research Group, Faculty of Psychology and Sport Sciences, Bielefeld University, \\ Bielefeld, Germany, ${ }^{4}$ Department of Health, Physical Education, and Recreation, University of Cape Coast, Cape Coast, \\ Ghana
}

\section{OPEN ACCESS}

Edited by: Iccha Basnyat,

James Madison University,

United States

Reviewed by:

Joan Pedro-Carañana,

Complutense University of

Madrid, Spain

Rasha El-Ibiary,

Future University in Egypt, Egypt

*Correspondence:

John Elvis Hagan Jr. elvis.hagan@ucc.edu.gh

Specialty section

This article was submitted to Health Communication,

a section of the journal

Frontiers in Communication

Received: 09 April 2020

Accepted: 08 June 2020

Published: 17 June 2020

Citation:

Ahinkorah BO, Ameyaw EK, Hagan JE

Jr, Seidu A-A and Schack T (2020)

Rising Above Misinformation or Fake News in Africa: Another Strategy to

Control COVID-19 Spread.

Front. Commun. 5:45.

doi: 10.3389/fcomm.2020.00045
Misinformation related to the COVID-19 pandemic is gradually gaining much popularity and amplifying the threat facing humanity about the continuous spread of the virus regardless of one's location. Although some of the influx of these falsehoods may be harmless, others might pose a serious threat by misleading the general population to depend on unjustified and/unsubstantiated claims for protection and show preference for them against scientifically proven guidelines. This paper provides a clear understanding on some COVID-19 misinformation, the inherent implications this poses to public health in Africa and highlights the potential strategies to curb this trend.

Keywords: misinformation, COVID-19, fake news, mass media, Africa

\section{INTRODUCTION}

Africa is one of the continents to be recently affected by the COVID-19 pandemic. From the very onset of the pandemic, there were some misconceptions that due to perhaps the geographical conditions (e.g., warm temperatures) of the continent, the causative organisms of the virus would not thrive. Another misleading information was that Africans may have strong immune systems to battle the virus (Ryder, 2020). However, the sudden rise of the pandemic across the continent debunks these earlier erroneous impressions. Since the first case of COVID-19 was noted on the 14th February, 2020 in Egypt, recent statistics reveal that the worst affected countries are South Africa (1,655 confirmed cases, 11 deaths); Algeria (1,432 confirmed cases, 173 deaths); Egypt (1,173 confirmed cases, 78 deaths); Morocco (1,120 confirmed cases, 80 deaths); Cameroon (658 confirmed cases, 9 deaths); Tunisia ( 574 confirmed cases, 22 deaths); Burkina Faso (345 confirmed cases, 17 deaths), Cote D'Ivoire (261confirmed cases, 3 deaths); Mauritius (244 confirmed cases, 7 deaths); Nigeria (232 confirmed cases, 5 deaths); Senegal (226 confirmed cases, 2 deaths), and Ghana (214 confirmed cases, 5 deaths) as at 18.00 GMT on Monday, April 6, 2020 (Coronavirus live tracker, 2020). These recent developments have raised serious public health concerns among the local populace. Of particular concern is the potential spread of the disease through multitude of false, misleading and/or unsubstantiated COVID-19 news contents to the general public termed as "misinformation." Misinformation can be defined as "any claim of fact that is currently false due to lack of scientific evidence" (Chou et al., 2018).

Due to the wave of fear, worry, and panic about local transmissions and multiple infections among the populace, several people are currently spreading a wide range of diverse misinformation 
through the internet, opinion leaders, political figures, and social commentators through unsubstantiated malicious information or fake news. The widespread misguided COVID-19 related misinformation can spread the disease quickly and can cause xenophobia on the continent (Mejova and Kalimeri, 2020; Shimizu, 2020; Thomas, 2020). The fear, worry, stigma, and other falsehoods about COVID-19 might lead to adverse impacts on disease control since prior SARS and Ebola outbreaks are clear examples (Maunder et al., 2003; Person et al., 2004; Cheung, 2015). Therefore, understanding the various forms of misinformation about COVID-19 and the threat it poses to the general public could be essential for various governments, public health officials as well as the media to design effective information campaigns and other pragmatic interventions. Strategies to circumvent around sharing of fake and misleading COVID-19 information are highlighted in this mini review.

\section{MISCONCEPTIONS AND/OR MISINFORMATION ON COVID-19}

Before connecting COVID-19 related misconceptions and misinformation, it critical for the purposes of scientific interest to provide a deeper insight of the mechanisms that may foster set of beliefs, their acceptance and/or rejection of somewhat false information. By providing deeper insights on the linkages between the concepts, a better understanding could also help guide interventions targeted at reducing incorrect beliefs on COVID-19 (Martel et al., 2019). Using the classical reasoning perspective, reasoning atypically support unearthing the truth of news content and that misconceptions and/ or misinformation frequently thrive by forcing people to be involved with news content in an emotional way rather than follow a logical path (Pennycook et al., 2020a). Hence, emotional reactions from people are less shrewd and more likely to stimulate belief in false content whilst analytical reasoning and reflection allow people to make sound judgment and correct false information.

Africa is besieged with so many misconceptions and/or misinformation about COVID-19 via the media, astute politicians, social commentators as well as the social media (Frenkel et al., 2020; Russonello, 2020). Various conspiracy theories on COVID-19 range from the creation of a biological weapon to break the economic power of China against other economically endowed nations like the US to the use of local herbs or products (e.g., coconut oil, ginger, garlic) to cure the virus have been asserted on various media platforms (Oxford Analytica, 2020a; Pennycook et al., 2020b). Therefore, the general public may be tempted to turn to unproductive, unsubstantiated and somewhat harmful medications for the cure of the virus. Additionally, people have either overreacted (e.g., hoard goods, hike prices of goods and services) and/ or more riskily, underreacted (e.g., willfully engage in risky behaviors) and unconsciously spread the virus by ignoring social isolation/distancing (Pennycook et al., 2020b). COVID-19 misinformation (i.e., misleading news content) and rumors are also masking other credible healthy behaviors like hand washing, social distancing and promoting incorrect practices that will potentially increase the virus spread. Another widespread myth currently in circulation is that home treatments can cure or prevent people from contracting the virus. Suggestions like taking doses of vitamin $\mathrm{C}$ and eating garlic as part of regular meals are welcomed as antidote to COVID-19 despite the lack of scientific evidence (Mian and Khan, 2020). Whereas, majority of these actions could be seen as harmless, some have been proven to be very hazardous. The American Food and Drug Administration has given serious caution to the general public on the use of sodium chloride mixture with citric acid, a solution purported on social media to have some antimicrobial, antiviral, and antibacterial properties. According to this agency, this solution causes severe vomiting, life-threatening low blood pressure, and acute liver failure (Frenkel et al., 2020). The consequence of such actions would lead to poor physical and mental health among the populace (Tasnim et al., 2020). For instance, health personnel in Nigeria identified numerous cases of Chloroquine (i.e., medicine used for treating malaria) overdose after alleged news from the media claimed its efficacy for the treatment of COVID-19 (Busari and Adebayo, 2020). Alleged national lockdowns in Europe, US, Africa and other locations triggered panic purchases at supermarkets, grocery shops, and other marketing outlets. These unusual phenomena have created interruptions in the supply chain and increased demand-supply loopholes and food insecurities (Spencer, 2020; Tasnim et al., 2020).

The biggest challenge is that these misinformation or fakes news are drowning official public health advice on COVID-19, making it extremely problematic for the voices of healthcare professionals to be heard, the implications of which may be enormous as the virus spreads between and within diverse populations (Oxford Analytica, 2020a). The worrying aspect is that the current socio-political climate in Africa has engineered the spread of the COVID-19 related misinformation through propagation of unsubstantiated news. Theses somewhat misleading COVID-19 news contents have been fabricated by number of persons and groups promoting nationalism and antiimmigration views through video messages, pictures, interviews and newspapers to provide false claims. Additionally, political actors have taken advantage of the situation to subdue their opponents and leverage on the virus outbreak for their political gain using the same channels of communication (Oxford Analytica, 2020b). Local scammers and internet bloggers have been creating web links to spread COVID-19 misrepresentations with provocative banners (i.e., headlines) to lure users to visit and make advertising revenue for the owners, or directly promote unverified treatment protocols or medications for COVID-19. Although statistics in Africa are not readily available, though may exist, the National Fraud Intelligence Bureau, UK reported COVID-19-related scam cost UK nationals over 800,000 pounds only in February, 2020. These unscrupulous activities may be pervasive in other societies (e.g., Africa) that have weak intelligence systems. Such activities if unchecked might increase as the number of coronavirus cases rise. This infodemic has prompted WHO to pay major attention by committing resources to deal with the bands of misinformation or fake news currently circulating on different media platforms which could hinder 
attempts by organizations and governments to control the spread of COVID-19. This misinformation could reduce public belief or trust in various governmental and other credible organizations' (e.g., World Health Organization) efforts to manage this global pandemic. Because social media platforms offer a broader landscape for COVID-19 misinformation for reaching a wider audience, WHO is working in close collaboration with social media firms to battle this challenge. Identified methods being used include using standardize fact-checking configurations, encouraging precise news content, and making incorrect content very difficult to find (Oxford Analytica, 2020b).

\section{TAKING THE RIGHT MESSAGES AND STRATEGIES TO CONTROL COVID-19 SPREAD}

Given that misinformation moves rapidly and more widely through different channels, the effective strategy against heightening public fear on misconstructions of the science and epidemiology of COVID-19 is the provision of accurate information that conveys consistently science-driven narratives (Garrett, 2020). Local community and health organizations, civil society, mass media as well as other support groups should endeavor to circulate accurate COVID-19 information. Realizing this goal requires strategic partnerships at local and global levels, integrating offline and online resources through coordinated efforts so that authorized information is circulated across different platforms (Tasnim et al., 2020). Specifically, ministries in charge of information and local media commissions should impose strict measures like demonetization against commercial misinformation creators (e.g., internet bloggers). Local governments could task technological companies in partnership with health institutions to build a centralized system that identifies abusers of youtube, facebook, and twitter. Running advertisements, including video messages that provide fake and/or unrealistic (i.e., false) medical claims to project COVID-19-related information for monetary gains should be intercepted and removed from media sharing platforms. These targets can also be achieved by the use of innovative technologies like natural language processing or text-mining methods to identify online content that has no empirical evidence. Data-mining algorithms have been effectively used to discover distinctive features of fake news or misinformation which were subsequently removed from specific platforms (Shu et al., 2017). New strategies that integrate existing fact-checking structures to promote accurate COVID-19 related information on practical preventive measures [e.g., frequent hand washing with soap, frequent use of hand sanitizers, continuous use of nose mask and other personal protective equipment (PPE), social distancing] should immediately be established. For instance, Facebook is currently making advertisements guiding consumers to local health authorities whereas google is championing WHO's websites when a search is conducted with virus's keywords. Other healthcare establishments and personnel could also dominate social media and other media platforms with precise information on the virus (Oxford Analytica, 2020a). Various local governments and media workers should use public health experts, especially those from their Center for Disease Control to precisely provide relevant and accurate information to avoid fear among the general public (Mian and Khan, 2020). According to Mian and partner, if health establishments (e.g., frontline workers) effectively control, educate, and deal with public worries, the level of cynicism among the populace often churn by some social commentators, political opponents, and internet bloggers could be reduced. Another stringent measure could be that personnel responsible for the production and propagation of such COVID-19 misinformation or fake news on online portals should be charged with public deceit and made to face the law to serve as deterrent to other potential culprits. Local and national governing authorities and law enforcement agencies should be notified of these problems so that necessary steps could be taken to carefully address them in different African regions. Cyber security is one area that Africa governments should also seek to develop in the wake of this current pandemic though may require huge financial investment.

This write-up is not without some limitations. First, although this "infodemic" may perhaps vary from country to country, the current situation regarding the pandemic makes it extremely difficult to collate within and between country specific trends and magnitude. Second, the lack of country specific misinformation in the review does not make it nationally representative, hence might restrict research accuracy. Despite these shortcomings, this conceptualized article has research, public, and policy relevance. Future empirical work could investigate within and between country trends and magnitude of misinformation or fake news related to COVID-19 on social media (e.g., twitter, facebook, youtube) using hashtags and keywords associated with the pandemic.

\section{CONCLUSIONS}

As Africa's COVID-19 situation becomes a public health dilemma with between and within country multiple transmissions, effective information governance across the general public should be upheld to replace any misinformation or fake news related to COVID-19. Regrettably, falsehoods on various media platforms will continue to surge high as COVID-19 lingers on. Therefore, the dissemination of misinformation can powerfully impact people's actions and change the value of the interventions employed by local governments through their health institutions and other stakeholders. While some misinformation or fakes news may be harmless, others might pose a serious threat by misleading the general populace to depend on these unwarranted claims for protection and/or prioritize them over scientifically proven procedures. Hence, very accurate information flow is vital for the ultimate benefit of Africa's diverse populations suffering from the psychosocial and health burden related to this pandemic. According to Pennycook et al. (2020b), giving regular prompts by various mass media platforms on the notion of accuracy might be enough to enhance people's sharing decisions related to COVID-19 information and ease the volume of misinformation on the virus. These mass media interventions could be enforced to help minimize the spread of COVID-19 misinformation. Lastly, every citizen regardless of his or her 
geographical location should unconditionally be entitled to accurate information and even now with a more compelling need, especially during this COVID-19 era where such content might have dire consequences on the general well-being of the people.

\section{REFERENCES}

Busari, S., and Adebayo, B. (2020). Nigeria Records Chloroquine Poisoning After Trump Endorses it for Coronavirus Treatment. CNN. Available online at: https://www.cnn.com/2020/03/23/africa/chloroquine-trump-nigeria-intl/ index.html (accessed April 2, 2020)

Cheung, E. Y. (2015). An outbreak of fear rumours and stigma: Psychosocial support for the Ebola virus disease outbreak in West Africa. Intervention 13, 45-84. doi: 10.1097/WTF.0000000000000079

Chou, W. Y. S., Oh, A., and Klein, W. M. (2018). Addressing healthrelated misinformation on social media. JAMA 320, 2417-2418. doi: 10.1001/jama.2018.16865

Coronavirus live tracker (2020). Available online at: http://corona.tuply.co.za (accessed April 6, 2020).

Frenkel, S., Alba, D., and Zhong, R. (2020). Surge of virus misinformation stumps Facebook and Twitter. The New York Times. Retrieved from https://www. nytimes.com/2020/03/08/technology/coronavirus-misinformation-socialmedia.html

Garrett, L. (2020). COVID-19: the medium is the message. Lancet 395, 942-943. doi: 10.1016/S0140-6736(20)30600-0

Martel, C., Pennycook, G., and Rand, D. (2019). Reliance on emotion promotes belief in fake news. PsyArXiv. doi: 10.31234/osf.io/a2ydw

Maunder, R., Hunter, J., Vincent, L., Bennett, J., Peladeau, N., Leszcz, M., et al. (2003). The immediate psychological and occupational impact of the 2003 SARS outbreak in a teaching hospital. CMAJ 168, 1245-51.

Mejova, Y., and Kalimeri, K. (2020). Advertisers jump on coronavirus Bandwagon: politics, news, and business. arXiv [Preprint]. arXiv, 2003.00923.

Mian, A., and Khan, S. (2020). Coronavirus: the spread of misinformation. BMC Med. 18, 1-2. doi: 10.1186/s12916-020-01556-3

Oxford Analytica (2020a). Misinformation Will Undermine Coronavirus Responses. Emerald Expert Briefings (Emerald Insights).

Oxford Analytica (2020b). Tech May Curb Virus Profiteering, Not Disinformation. Emerald Expert Briefings (Emerald Insights).

Pennycook, G., Epstein, Z., Mosleh, M., Arechar, A. A., Eckles, D., and Rand, D. G. (2020a). Understanding and reducing the spread of misinformation online. PsyArXiv Working Paper, 1-63. doi: 10.31234/OSF.IO/3N9U8

Pennycook, G., McPhetres, J., Zhang, Y., and Rand, D. (2020b). Fighting COVID-19 misinformation on social media: Experimental evidence for a

\section{AUTHOR CONTRIBUTIONS}

BA, JH, EA, and A-AS conceived the work. BA, JH, EA, A-AS, and TS wrote and drafted the manuscript. All authors read and approved the final version of the manuscript.

scalable accuracy nudge intervention. PsyArXiv Preprints. doi: 10.31234/osf.io/ uhbk9

Person, B., Sy, F., Holton, K., Govert, B., Liang A, Garza, B., et al. (2004). Fear and stigma: the epidemic within the SARS outbreak. Emerg. Infect. Dis. 10, 358-363. doi: 10.3201/eid1002.030750

Russonello, G. (2020). Afraid of coronavirus? That might say something about your politics. The New York Times. Retrieved from https://www.nytimes.com/2020/ 03/13/us/politics/coronavirus-trump-polling.html

Ryder, H. (2020). COVID-19 Is Only Slowly Reaching Africa. That's No Surprise. The Africa report Available online at: https://www.theafricareport.com/24160/ covid-19-is-only-slowly-reaching-africa-thats-no-surprise/ (accessed March 24, 2020).

Shimizu, K. (2020). 2019-nCoV, fake news, and racism. Lancet. 395, 685-686. doi: 10.1016/S0140-6736(20)30357-3

Shu, K., Sliva, A., Wang, S., Tang, J., and Liu, H. (2017). Fake news detection on social media. ACM SIGKDD Explor Newsl. 19:22-36. doi: $10.1145 / 3137597.3137600$

Spencer, S. H. (2020). False Claims of Nationwide Lockdown for COVID19. Available online at: https://www.factcheck.org/2020/03/false-claims-ofnationwide-lockdown-for-covid-19/

Tasnim, S., Hossain, M. M., and Mazumder, H. (2020). Impact of rumors or misinformation on coronavirus disease (COVID-19) in social media. J. Prev. Med. Public Health. 53, 171-174. doi: 10.31235/osf.io/uf3zn

Thomas, Z. (2020). Misinformation on Coronavirus Causing 'Infodemic'. Available online at: https://www.bbc.com/news/technology-51497800 (accessed March 9, 2020).

Conflict of Interest: The authors declare that the research was conducted in the absence of any commercial or financial relationships that could be construed as a potential conflict of interest.

Copyright (C) 2020 Ahinkorah, Ameyaw, Hagan, Seidu and Schack. This is an openaccess article distributed under the terms of the Creative Commons Attribution License (CC BY). The use, distribution or reproduction in other forums is permitted, provided the original author(s) and the copyright owner(s) are credited and that the original publication in this journal is cited, in accordance with accepted academic practice. No use, distribution or reproduction is permitted which does not comply with these terms. 